\title{
Anomeric Proton and Carbon (H1-C1) NMR Chemical Shifts of Antigenic Mannans Obtained from Pathogenic Yeast Candida tropicalis
}

\author{
Takuya Kuraoka $^{1}{ }^{\circledR}$, Takayoshi Yamada ${ }^{1}$, Yuki Takatsutsumi ${ }^{1}$, Yukiko Ogawa ${ }^{2}$, \\ Hidemitsu Kobayashi ${ }^{*}$
}

${ }^{1}$ Divisions of Microbiology, Department of Pharmaceutical Science, Nagasaki International University, Nagasaki, Japan ${ }^{2}$ Divisions of Infection Control and Prevention, Department of Pharmaceutical Science, Nagasaki International University, Nagasaki, Japan

Email: ^h-kobaya@niu.ac.jp

How to cite this paper: Kuraoka, T., Yamada, T., Takatsutsumi, Y., Ogawa, Y. and Kobayashi, H. (2021) Anomeric Proton and Carbon (H1-C1) NMR Chemical Shifts of Antigenic Mannans Obtained from Pathogenic Yeast Candida tropicalis. Advances in Microbiology, 11, 296-301.

https://doi.org/10.4236/aim.2021.115022

Received: March 30, 2021

Accepted: May 23, 2021

Published: May 26, 2021

Copyright $\odot 2021$ by author(s) and Scientific Research Publishing Inc. This work is licensed under the Creative Commons Attribution International License (CC BY 4.0).

http://creativecommons.org/licenses/by/4.0/ (c) (i) Open Access

\begin{abstract}
On two dimensional maps of ${ }^{1} \mathrm{H}-{ }^{13} \mathrm{C}$ correlation spectroscopy (H-C COSY) analysis for the mannan of Candida tropicalis, nine cross peaks of anomeric proton and carbon were useful for the purpose of obtaining information on the chemical structure of this molecule. Namely, the mannans was comb-like structure constructed with the linear $\alpha$-1,6-linked polymannnosyl backbone and several oligomannnosyl side chains composed of $\alpha-1,2-, \alpha-1,3-$, and $\beta-1,2-$ linkages. Therefore, in the structural investigation of comb-like mannan, twodimensional $\mathrm{H}-\mathrm{C}$ COSY analysis is as useful as two-dimensional nuclear Hartmann-Hahn (HOHAHA) analysis.
\end{abstract}

\section{Keywords}

Candida tropicalis, Cell Wall Mannan, Comb-Like Structure,

${ }^{1} \mathrm{H}-{ }^{13} \mathrm{C}$ Correlation Spectroscopy, Anomeric Carbon Chemical Shift, $\alpha$-1,3-Linked Mannose

\section{Introduction}

Most of the antigenic activity of pathogenic Candida yeasts is carried out by $N$-linked polysaccharides composed of mannose that cover the outermost layer of their cell walls [1]. Therefore, structural studies on cell wall mannan of pathogenic Candida yeast have been actively conducted for the purpose of diagnosing candidiasis and searching for target antigens for yeast species identification [2] [3] [4] [5]. 
Nuclear magnetic resonance (NMR) analysis plays a major role in the study of the chemical structure of Candida yeast cell wall mannan. In recent years, it has become possible to determine the approximate overall structure of a mannan simply by performing a two-dimensional homonuclear Hartmann-Hahn (2D-HOHAHA) analysis of intact mannan molecule [6] [7]. This is because the nuclear Overhauser effect (NOE) cross-peak of various intact mannans and/or derived manno-oligosaccharides were sequentially assigned in two-dimensional maps such as nuclear Overhauser enhancement and exchange spectroscopy (NOESY) by Shibata et al. [8] [9] [10] and Kobayashi et al. [11] [12]

Candida tropicalis is one of the species that is often clinically isolated as a deep-seated mycosis-causing yeast. The cell wall mannan of this yeast is basically a comb-like structure in which several side chains are linked to linear backbone composed of $\alpha$-1,6-linked mannose residues [13]. There are two types of these side chains, one consisting of $\alpha-1,2$ - and $\beta$-1,2-linked mannose residues [6], and the other containing $\alpha$-1,3-linked mannose residues in addition to these mannose residues [14].

In this short report, we note that information on the two types of mannan structures from Candida tropicalis can be fully analyzed by two-dimensional ${ }^{1} \mathrm{H}-{ }^{13} \mathrm{C}$ correlation (H-C COSY) spectroscopy, which is not inferior to two-dimensional HOHAHA.

\section{Materials and Methods}

Candida tropicalis NBRC 0199 and 1400 strains were obtained from the National Institute of Technology and Evaluation, Chiba, Japan. These strains were maintained on Sabouraud agar slants. Cultivation of two C. tropicalis strains and preparation of mannan were performed as described [13]. These strains were cultivated in Sabouraud liquid medium at $27^{\circ} \mathrm{C}$ for $72 \mathrm{~h}$ on a reciprocal shaker.

Preparation of mannan was conducted by a combination of hot-water extraction and Fehling solution method [15]. The purified mannans obtained from the cells of the C. tropicalis NBRC 0199 and 1400 were designated Fr. 0199 and Fr. 1400 , respectively.

${ }^{1} \mathrm{H}$-NMR spectrum (internal acetone, $2.217 \mathrm{ppm}$ ) was measured with a Jeol JNM-GSX 400 spectrometer on solutions ( $3-10 \mathrm{mg}$ sample/0.7mL) in $\mathrm{D}_{2} \mathrm{O}$ at $70^{\circ} \mathrm{C}[16] .{ }^{13} \mathrm{C}-\mathrm{NMR}$ spectrum (internal $\mathrm{CD}_{3} \mathrm{OD}, 49.00 \mathrm{ppm}$ ) was measured with the same spectrometer on solutions $(15-25 \mathrm{mg}$ sample $/ 0.7 \mathrm{~mL})$ in $\mathrm{D}_{2} \mathrm{O}$ at $55^{\circ} \mathrm{C}$ [17]. Two-dimensional $\mathrm{H}-\mathrm{C}$ COSY was also recorded under the same conditions as for the ${ }^{1} \mathrm{H}$ - and ${ }^{13} \mathrm{C}-\mathrm{NMR}$ spectra in accordance with previous description [18].

\section{Results and Discussion}

Eight anomeric H1-C1 cross-peaks on a H-C COSY two-dimensional map of Fr. 0199 (Figure 1(a) and Table 1) were assigned based on the previous report [6]. The presence of cross-peak 1, 2, and 7 indicates that mannan contain $\beta$-1,2-linked oligomannosyl side chains. Cross-peaks 5 or 3 correspond to the 2-O-substituted 
or unsubstituted forms of the backbone in which $\alpha$-1,2-linked mannose residues are polymerized, respectively. The existence of internal $\alpha$-1,2-linked mannose residues was confirmed by the appearance of cross-peaks 8 , and 9 . The appearance of cross-peak 4 indicates the presence of a non-reducing terminal $\alpha$-1,2linked mannose residue of long side chain. On the other hand, in the two-dimensional map of Fr. 1400 (Figure 1(b) and Table 1), the appearance of an additional cross-peak 6 indicates the presence of non-reducing terminal $\alpha$-1,3-linked mannose residue. Summarizing these analysis results, the overall structure of $C$. tropicalis NBRC 0199 and 1400 strain mannans can be proposed as shown in Figure 2.

Table 1. Identification of chemical shifts of ${ }^{13} \mathrm{C}-{ }^{1} \mathrm{H}$ COSY spectrum of Fr. 0199 and Fr. 1400 .

\begin{tabular}{cccc}
\hline $\begin{array}{c}\text { Cross- } \\
\text { Peak }\end{array}$ & \multicolumn{2}{c}{${\text { Chemical shift }(\mathrm{ppm})^{\mathrm{a}}}^{\mathrm{a}}$} & Sugar residue $^{\mathrm{b}}$ \\
\cline { 2 - 4 } 1 & $\mathrm{H}-1$ & $\mathrm{C}-1$ & $\mathrm{M} \beta 1-2(\mathrm{M} \beta 1-2)$ \\
2 & 4.839 & 101.82 & $\mathrm{M} \beta 1-2 \mathrm{M} \beta 1-2 \mathrm{M} \beta 1$ \\
3 & 4.915 & 99.86 & $\alpha 1-6 \mathrm{M} \alpha 1-6$ \\
4 & 4.915 & 100.31 & $\mathrm{M} \alpha 1-2 \mathrm{M}$ \\
5 & 5.055 & 102.98 & $\alpha 1-6 \mathrm{M} \alpha 1-6$ \\
& & & $\mathrm{M} \alpha 1$ \\
6 & 5.083 & 99.18 & $\mathrm{M} \alpha 1-3 \mathrm{M} \alpha 1$ \\
7 & 5.145 & 102.86 & $(\beta 1-2 \mathrm{M}) \beta 1-2 \mathrm{M} \alpha 1-2$ \\
8 & 5.145 & 100.81 & $(\alpha 1-2 \mathrm{M}) \alpha 1-2 \mathrm{M} \alpha 1-2$ \\
9 & 5.244 & 101.39 & $\mathrm{M} \alpha 1-2 \mathrm{M} \alpha 1-2 \mathrm{M} \alpha 1$ \\
\hline
\end{tabular}

${ }^{\mathrm{a}}$ Measured using acetone $(2.217 \mathrm{ppm})$ as a standard; ${ }^{\mathrm{b}} \mathrm{M}$ denotes a D-mannose residue.

(a)

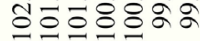

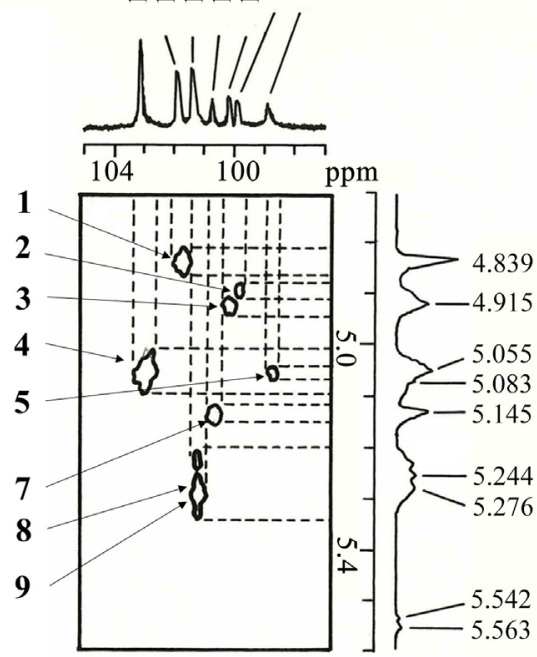

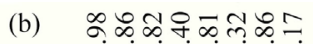
의의응ㅇㅇㅇำ
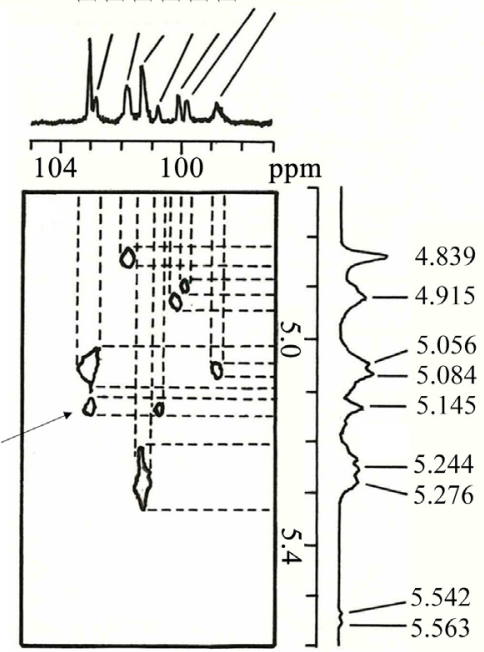

Figure 1. H-C COSY (anomeric region) spectra of Fr. 0199 (a) and Fr. 1400 (b). 


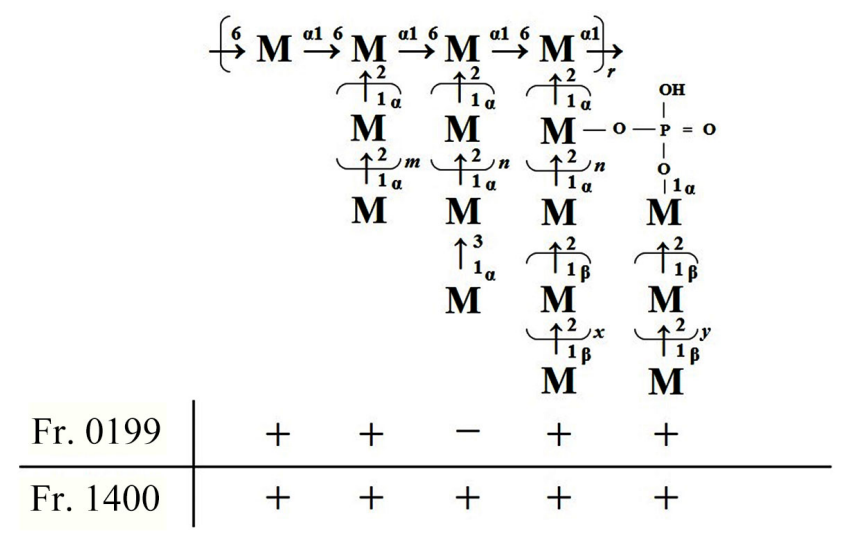

Figure 2. Approximate overall structures of Fr. 0199 and Fr. 1400. M denotes a D-mannose. Polymerization of mannan unit $r$ was not determined. The estimated polymerization degrees of the side chains were $m=0-4, n \geq 2, x \geq 1$ and $y \geq 0$, respectively.

In the previous study [18], it was shown to be suitable to analyze the comblike yeast mannan composed of $\alpha-1,2-, \beta$-1,2- and $\alpha$-1,6-linked mannose residues by two-dimensional $\mathrm{H}-\mathrm{C}$ COSY. In this report, we have shown that this procedure is also useful in the structural analysis of similar mannan composed of $\alpha-1,2-, \alpha-1,3-, \beta-1,2-$, and $\alpha-1,6-$ linked mannose residues. However, in the single NMR analysis of undegraded mannan, the degrees of polymerization of the $\alpha-1,2-$ and $\beta$-1,2-linked mannose residues constituting the side chains ( $x$ and $y$ values in Figure 2) cannot be identified. The only way to obtain such accurate information is to perform a hydrolysis method such as acetolysis on mannan and analyze the resultant oligosaccharides corresponding to the mannan side chains.

\section{Conclusion}

In the NMR analysis of yeast cell wall mannan, the $\mathrm{H} 1-\mathrm{C} 1$ cross-peaks of $\mathrm{H}-\mathrm{C}$ COSY two-dimensional map give almost the same value of information as the H1-H2 cross-peaks of two-dimensional HOHAHA map. However, if there is a need to measure the degree of polymerization of the side chains in the mannan molecules, since not enough two-dimensional NMR analysis, will occur need to perform a partial acid-hydrolysis such as acetolysis on the mannan.

\section{Conflicts of Interest}

The authors declare no conflicts of interest regarding the publication of this paper.

\section{References}

[1] Fukazawa, Y., Shinoda, T. and Tsuchiya, T. (1968) Response and Specificity of Antibodies for Candida albicans. Journal of Bacteriology, 95, 754-763. https://doi.org/10.1128/JB.95.3.754-763.1968

[2] Shibata, N., Kobayashi, H. and Suzuki, S. (2012) Immunochemistry of Pathogenic Yeast, Candida Species, Focusing on Mannan. Proceedings of the Japan Academy, 
Series B. Physical and Biological Sciences, 88, 250-265.

https://doi.org/10.2183/pjab.88.250

[3] Poulain, D., Faille, C., Delaunoy, C., Jacquinot, P.M., Trinel, P.A. and Camus, D. (1993) Probable Presence of $\beta$ (1-2)-Linked Oligomannosides That Act as Human Immunoglobulin G3 Epitopes and Are Distributed over a Candida albicans 14- to 18-Kilodalton Antigen. Infection and Immunity, 61, 1164-1166. https://doi.org/10.1128/IAI.61.3.1164-1166.1993

[4] Gorin, P.A.J. and Perlin, A.S. (1956) A Mannan Produced by Saccharomyces rouxii. Canadian Journal of Chemistry, 34, 1796-1803. https://doi.org/10.1139/v56-232

[5] Kogan, G., Pavliak, V., Sandula, J. and Masler, L. (1991) Structure of the Cell Wall Mannans of the Pathogenic Yeasts of Candida Species. A Complex Insight. Carbohydrate Polymers, 14, 65-76. https://doi.org/10.1016/0144-8617(90)90007-F

[6] Kobayashi, H., Oyamada, H., Matsuda, K., Shibata, N. and Suzuki, S. (2003) Distribution of Antigenic Oligomannosyl Side Chains in the Cell Wall Mannans of Several Strains of Candida tropicalis. Archives of Microbiology, 180, 76-80. https://doi.org/10.1007/s00203-003-0550-7

[7] Kobayashi, H., Kawakami, S., Ogawa, Y., Shibata, N. and Suzuki, S. (2013) Isolation of Manno-Oligosaccharides Corresponding to Antigenic Determinants of Pathogenic Yeast Candida catenulata Cell Wall Mannan. Advances in Microbiology, 3, 222-226. https://doi.org/10.4236/aim.2013.32033

[8] Shibata, N., Hisamichi, K., Kikuchi, T., Kobayashi, H., Okawa, Y. and Suzuki, S. (1992) Sequential Nuclear Magnetic Resonance Assignment of Beta-1,2-Linked Mannooligosaccharides Isolated from the Phosphomannan of the Pathogenic Yeast Candida albicans NIH B-792 Strain. Biochemistry, 31, 5680-5686.

https://doi.org/10.1021/bi00139a036

[9] Shibata, N., Hisamichi, K., Kobayashi, H. and Suzuki, S. (1993) Complete Assignment of ${ }^{1} \mathrm{H}$ and ${ }^{13} \mathrm{C}$ Nuclear Magnetic Resonance Chemical Shifts of $\beta$-1,2-Linked Mannooligosaccharides Isolated from the Phosphomannan of the Pathogenic Yeast Candida albicans NIH B-792 Strain. Archives of Biochemistry and Biophysics, 302, 113-117. https://doi.org/10.1006/abbi.1993.1188

[10] Shibata, N., Akagi, R., Hosoya, T., Kawahara, K., Suzuki, A., Ikuta, K., Kobayashi, H., Hisamichi, K., Okawa, Y. and Suzuki, S. (1996) Existence of Novel Branched Side Chains Containing $\beta-1,2$ and $\alpha-1,6$ Linkages Corresponding to Antigenic Factor 9 in the Mannan of Candida guilliermondii. Journal of Biological Chemistry, 271, 9259-9266. https://doi.org/10.1074/jbc.271.16.9259

[11] Kobayashi, H., Komido, M., Watanabe, M., Matsuda, K., Suzuki, M., Ikeda, T. Oyamada, H., Shibata, N. and Suzuki, S. (1994) Structure of Cell Wall Mannan of Candida kefyr IFO 0586. Infection and Immunity, 62, 4425-4431.

https://doi.org/10.1128/IAI.62.10.4425-4431.1994

[12] Kobayashi, H., Suzuki, J., Tanaka, S., Kiuchi, Y., Oyamada, H., Iwadate, N., Suzuki, H., Shibata, N., Suzuki, S. and Okawa, Y. (1997) Structure of a Cell Wall Mannan from the Pathogenic Yeast, Candida catenulata: Assignment of ${ }^{1} \mathrm{H}$ Nuclear Magnetic Resonance Chemical Shifts of the Inner $\alpha$-1,6-Linked Mannose Residues Substituted by a Side Chain. Archives of Biochemistry and Biophysics, 341, 70-74. https://doi.org/10.1006/abbi.1997.9939

[13] Kobayashi, H., Matsuda, K., Ikeda, T., Suzuki, M., Takahashi, S., Shibata, N. and Suzuki, S. (1994) Structures Study of Cell Wall Mannans Isolated from Pathogenic Yeast Candida tropicalis IFO 0199 and 1647 Strains. Infection and Immunity, 62, 615-622. https://doi.org/10.1128/IAI.62.2.615-622.1994 
[14] Kuraoka, T., Yamada, T., Ishiyama, A., Oyamada, H., Ogawa, Y. and Kobayashi, H. (2020) Determination of $\alpha$-1,3-Linked Mannose Residue in the Cell Wall Mannan of Candida tropicalis NBRC 1400 Strain. Advances in Microbiology, 10, 14-26. https://doi.org/10.4236/aim.2020.101002

[15] Kobayashi, H., Shibata, N. and Suzuki, S. (1986) Acetolysis of Pichia pastoris IFO 0948 Strain Mannan Containing $\alpha-1,2$ and $\beta$-1,2 Linkages Using Acetolysis Medium of Low Sulfuric Acid Concentration. Archives of Biochemistry and Biophysics, 245, 494-503. https://doi.org/10.1016/0003-9861(86)90242-0

[16] Kobayashi, H., Shibata, N., Mitobe, H., Ohkubo, Y. and Suzuki, S. (1989) Structural Study of Phosphomannan of Yeast-Form Cells of Candida albicans J-1012 Strain with Special Reference to Application of Mild Acetolysis. Archives of Biochemistry and Biophysics, 272, 364-375. https://doi.org/10.1016/0003-9861(89)90230-0

[17] Kobayashi, H., Shibata, N., Nakada, M., Chaki, S., MIzugami, K., Ohkubo, Y. and Suzuki, S. (1990) Structural Study of Cell Wall Phosphomannan of Candida albicans NIH B-792 (Serotype B) Strain, with Special Reference to ${ }^{1} \mathrm{H}$ and ${ }^{13} \mathrm{C}$ NMR Analyses of Acid-Labile Oligomannosyl Residues. Archives of Biochemistry and Biophysics, 278, 195-204. https://doi.org/10.1016/0003-9861(90)90248-W

[18] Kuraoka, T., Shukuri, M., Iwanaga, S., Yamada, T., Ogawa, Y. and Kobayashi, H. (2019) Distribution of Oligomannosyl Side Chains in the Cell Wall Mannan of Pichia pastoris Purified by Benanomicin A. International Journal of Current Microbiology and Applied Sciences, 8, 2926-2935.

https://doi.org/10.20546/ijcmas.2019.801.311

\section{Abbreviations}

NMR: Nuclear magnetic resonance

$\mathrm{H}-\mathrm{C}$ COSY: ${ }^{1} \mathrm{H}-{ }^{13} \mathrm{C}$ correlation spectroscopy

HOHAHA: Nuclear Hartmann-Hahn

NOE: Nuclear Overhauser effect

NOESY: Nuclear Overhauser enhancement and exchange spectroscopy 